\title{
Adherence, exposure and patients' experiences with the use of erlotinib in non-small cell lung cancer
}

\author{
Lonneke Timmers $\cdot$ Christel C. L. M. Boons $\cdot$ J. Moes-ten Hove $\cdot$ Egbert F. Smit \\ Peter M. van de Ven · Joachim G. Aerts · Eleonora L. Swart • Epie Boven · \\ Jacqueline G. Hugtenburg
}

Received: 7 December 2014 / Accepted: 7 February 2015 / Published online: 6 March 2015

(C) The Author(s) 2015. This article is published with open access at Springerlink.com

\begin{abstract}
Purpose Erlotinib is an orally administered tyrosine kinase inhibitor used for treatment of non-small cell lung cancer. Understanding actual use of medication is essential for optimizing treatment conditions.

Methods In this multicentre prospective observational study, patients starting erlotinib treatment were followed for 4 months. Adherence was assessed using a medication event monitoring system (MEMS). Area under the curve (AUC) was determined after 1, 2 and 4 months. Before start and at monthly intervals, patients filled out questionnaires about attitude towards medication and disease, quality of life, symptoms and use in daily practice.

Results Sixty-two patients (median age 63.5 years, $53 \%$ male) were included of whom 15 were still on treatment after 4 months. MEMS data of 55 patients revealed a mean adherence of $96.8 \pm 4.0 \%$. Over one-third of patients had an adherence rate $<95 \%$. At 1 month, $21 \%$ of patients did
\end{abstract}

L. Timmers $(\varangle) \cdot$ C. C. L. M. Boons · J. Moes-ten Hove ·

E. L. Swart · J. G. Hugtenburg

Department of Clinical Pharmacology and Pharmacy,

VU University Medical Center, De Boelelaan 1117, 1081

HV Amsterdam, The Netherlands

e-mail: L.Timmers@vumc.nl

E. F. Smit

Department of Pulmonology, VU University Medical Center,

Amsterdam, The Netherlands

P. M. van de Ven

Department of Epidemiology and Biostatistics, VU University

Medical Center, Amsterdam, The Netherlands

J. G. Aerts

Department of Pulmonology, Erasmus University Medical

Center, Rotterdam, The Netherlands not always correctly take erlotinib without food. Associated risk factors were older age, suboptimal adherence, ocular symptoms and stomatitis (all $p<0.05$ ). After 1 month of treatment, fatigue $(91 \%)$ and rash $(86 \%)$ were the most common symptoms reported. $\mathrm{AUC}_{\mathrm{ss}}$ of erlotinib was higher in patients with rash and patients with moderate-severe anorexia (both $p<0.05$ ).

Conclusion Though adherence to erlotinib treatment is generally high, non-adherence might be an issue in a considerable number of patients. To support optimal erlotinib intake, clinicians need to take adequate measures to ameliorate symptoms and to address adherence and correct intake without food. Especially older patients and those who experience stomatitis may need extra attention.

Keywords Erlotinib - Non-small cell lung cancer · Medication adherence $\cdot$ Symptoms $\cdot$ Patient-reported . Tyrosine kinase inhibitor

\section{J. G. Aerts}

Department of Pulmonology, Amphia Hospital Breda, Breda, The Netherlands

\section{E. Boven}

Department of Medical Oncology, VU University Medical Center, Amsterdam, The Netherlands

\section{J. G. Hugtenburg}

The EMGO Institute for Health and Care Research, VU

University Medical Center, Amsterdam, The Netherlands 


\section{Introduction}

Erlotinib is an orally administered tyrosine kinase inhibitor (TKI) of the epidermal growth factor receptor (EGFR) indicated as first-line treatment for advanced non-small cell lung cancer (NSCLC) in patients with activating EGFR mutations and as second- and third-line treatment in patients with EGFR wild-type NSCLC. In the pivotal study, erlotinib prolonged survival, reduced tumourrelated adverse events and improved quality of life (Shepherd et al. 2005; Bezjak et al. 2006). Response to erlotinib is highly dependent on the mutation status of EGFR in tumour tissue (Cadranel et al. 2012; Petrelli et al. 2012a). The prognosis is particularly poor in patients with EGFR wild-type, while substantially better in patients with EGFR mutations treated first line with erlotinib (Petrelli et al. 2012a). The most common adverse events of erlotinib occurring in $>10 \%$ of patients are skin rash, anorexia, diarrhoea, (kerato) conjunctivitis and fatigue (EMA 2014; Shepherd et al. 2005). In another meta-analysis of 24 trials in which the EGFR mutation status was not taken into account, skin rash was found to be an independent predictive factor for survival and progression (Petrelli et al. 2012b). In addition, patients who developed grade 2-4 rash had a higher chance to respond to treatment as compared to patients without rash (Petrelli et al. 2012b). Dose increase to achieve rash in individual patients, however, has resulted in controversial findings (Mita et al. 2011; Brahmer et al. 2014). From a patient's view, druginduced symptoms may induce considerable physical and psycho-social discomfort, which in daily practice are known to affect medication adherence (Verbrugghe et al. 2013; Sabaté 2003). Non-adherence may lead to suboptimal clinical outcomes and increased healthcare costs (Sabaté 2003).

Adherence rates of patients using oral anti-cancer agents have been shown to range from less than 20 to $100 \%$ (Partridge et al. 2002; Ruddy et al. 2009). Understanding of patients' actual use of medication is essential for creating treatment conditions that will provide optimal clinical benefit. Patient-reported outcomes therefore should be taken into consideration in the treatment decision-making process as they better reflect daily health status than adverse event assessments by clinicians (Basch et al. 2009; Basch 2010). At present, little is known about the use of erlotinib in daily practice from the patients' perspective. This study in patients with advanced or metastatic NSCLC was designed to assess adherence to erlotinib treatment and evaluate experiences of patients as well as the relationship between medication adherence, erlotinib exposure and symptoms (Timmers et al. 2011).

\section{Patients and methods}

Study design

This prospective observational cohort study (Timmers et al. 2011) was conducted between October 2009 and July 2011 in 12 Dutch hospitals. Patients with advanced NSCLC scheduled for treatment with erlotinib regardless their EGFR mutation status were eligible for participation. Exclusion criteria were: age younger than 18 years or inability to fill out a Dutch questionnaire. Patients starting erlotinib were followed for a maximum of 4 months. Adherence to erlotinib was measured with a medication event monitoring system (MEMS). Blood samples were collected after 1, 2 and 4 months. Patients filled out questionnaires before the start of erlotinib and at monthly intervals on treatment. The study was approved by the Medical Ethics review board of VU University Medical Center (VUMC, Amsterdam, The Netherlands), as well as the Medical Ethics review board of each participating centre. Written informed consent was obtained from all patients.

\section{Data collection}

\section{Medication adherence}

Adherence was measured using MEMS (SIMpill ${ }^{\circledR}$, Evalan, Amsterdam, The Netherlands). This pill box contains an electronic processor that records all time-points the box is opened. MEMS data were used for observational purposes only. Only MEMS data from patients who used erlotinib $>7$ days were included for this analysis. Adherence was expressed as the proportion of days covered (PDC) and was calculated by the number of days on which the box was opened divided by the total number of days of treatment (for a maximum of 4 months) $\times 100 \%$. To calculate the proportion of days with multiple openings (PDMO), the number of days on which the box was opened at least twice was divided by the total number of days of treatment (for a maximum of 4 months) $\times 100 \%$. Multiple openings on the first and last day of use were not considered for calculation of PDMO.

\section{Erlotinib AUC}

A steady-state blood sample was collected at regular visits after 1, 2 and 4 months of treatment in those patients taking erlotinib $150 \mathrm{mg} /$ day. The time of blood withdrawal and the time of the last ingestion of erlotinib before blood sampling were registered. Samples were centrifuged, and the plasma was stored at $-20{ }^{\circ} \mathrm{C}$ until analysis. 
Plasma concentrations of erlotinib were analysed by a validated liquid chromatography MS/MS method. The lower limit of quantification (LLOQ) was set at $7 \mathrm{ng} /$ $\mathrm{ml}$. For post hoc estimation of the area under the curve $(0-24 \mathrm{~h})$ at steady state $\left(\mathrm{AUC}_{\mathrm{ss}}\right)$, the data were analysed with the NONMEM program (version VII, level 2 ICON), using a one-compartment first-order absorption and elimination model adapted from the model described by $\mathrm{Lu}$ et al. (2006). The bioavailability F was set at 1 . The typical population values for the parameters: absorption constant, $\mathrm{Ka}\left(0.89 \mathrm{~h}^{-1}\right)$, clearance $(4.29 \mathrm{~L} / \mathrm{h})$ and volume of distribution V (210 L) were set according to the publication of $\mathrm{Lu}$ et al. Covariates (total bilirubin, $\alpha 1$-acid glycoprotein, smoking) in the model were tested with backward elimination for our population. Selection of the covariates of the model was based on the likelihood ratio test. The objective function value $(\mathrm{OFV})$ is proportional to -2 times the $\log$ likelihood of the data, given the model; therefore, the difference between two hierarchic models in OFV $(\triangle \mathrm{OFV})$ is approximately $\chi^{2}$-distributed. A $\triangle \mathrm{OFV}$ between the competing models of $3.84(\mathrm{~d} f=1)$, corresponding to a nominal $p$ value of $<0.05$, was required for the more complex model to be regarded as significantly better than the less complex one. After the model was selected, systemic exposure to erlotinib as $\mathrm{AUC}_{\mathrm{ss}}$ was calculated.

\section{Questionnaires}

At baseline, patients were asked to fill out questionnaires including demographic characteristics, smoking, co-medication (including acid-inhibiting medication), quality of life [Short Form-12 Health Survey (SF-12)] (Aaronson et al. 1998; Gandek et al. 1998), attitude towards medication in general and specifically towards erlotinib (Beliefs about Medicines Questionnaire [BMQ]) (Horne et al. 1999), illness perception (Brief Illness Perception Questionnaire [Brief IPQ]) (Broadbent et al. 2006) and symptoms. After each month of treatment, patients filled out questionnaires about adherence behaviour (Medication Adherence Report Scale [MARS]) (Butler et al. 2004; Horne et al. 2001), overuse, erlotinib intake in relation to food intake, quality of life, illness perception, patients' attitude towards medication in general and specifically towards erlotinib and symptoms. Intake of erlotinib in relation to food intake was scored as incorrect when patients reported taking erlotinib $<60 \mathrm{~min}$ before or $<120 \mathrm{~min}$ after food intake. The questions on symptoms were distracted from the literature on erlotinib toxicities occurring in $>10 \%$ of patients, and answers were scored on a 5 point Likert scale (not at all, a little bit, rather, a lot, very much). The scores at baseline and the scores during use were considered as, respectively, baseline health problems and patient-reported symptoms. Patient-reported symptoms scored as 'a lot' or 'very much' were considered as 'severe'. Patients taken off treatment before the end of the four-month follow-up period were asked to fill out questions about reasons for discontinuation.

\section{Patients' medical file}

Information on disease characteristics and dose adjustment or interruption by the physician was derived from the patients' medical file.

\section{Statistics}

Baseline descriptive data were analysed as frequencies (percentages) for categorical variables and as the mean ( \pm standard deviation) for continuous data. Adherence over time was summarized by mean PDC and mean PDMO per time-period. Associations between baseline characteristics and incorrect use of erlotinib separately from food were assessed in univariate logistic regression analyses in which incorrect use was taken as the dependent variable. Associations between repeatedly measured variables and incorrect intake of erlotinib over time were tested using generalized estimating equation analyses (GEE). The nonparametric Mann-Whitney test was used to compare the AUC of patients with and without symptoms and patients using and not using acid-inhibiting medication (i.e. proton-pump inhibitors or histamine H2-receptor antagonists) at one month. For the comparison between patients with or without symptoms, two separate analyses were performed using different cut-off points: 'not at all' versus 'any symptom', and 'not at all' or 'a little bit' (no and mild) versus 'rather', 'a lot', or 'very much' (moderate and severe). The Fisher exact test was used to compare patient-reported symptoms from the present study with adverse events as reported in the BR.21 clinical trial using the Common Terminology Criteria for Adverse Events (CTCAE) system (vs. 2) (Shepherd et al. 2005). For all analyses, a two-tailed significance level of 0.05 was used. $p$ values below this level were considered statistically significant. The statistical analyses were performed with SPSS 20.0 for Windows (IBM Corp, Armonk, NY, USA).

\section{Results}

Baseline characteristics

A total of 62 patients (median age 63.5 years; $53 \%$ male) were included, of whom 15 were still on treatment after 4 months. With the exception of 2 patients, all patients started with a once daily dose of $150 \mathrm{mg}$. Thirteen (22\%) dropped out before the measurement at 1 month and 33 
Table 1 Number of patients for which data are available at timepoint

\begin{tabular}{llllll}
\hline & $T 0$ & $T 1$ & $T 2$ & $T 3$ & $T 4$ \\
\hline Patients on treatment & 62 & 49 & 29 & 17 & 15 \\
Adherence MEMS & 55 & 45 & 27 & 16 & 14 \\
Blood sample & $\mathrm{x}$ & 42 & 28 & $\mathrm{x}$ & 13 \\
Questionnaire & 62 & 47 & 27 & 17 & 14 \\
MEMS + blood sample & $\mathrm{x}$ & 39 & 26 & $\mathrm{x}$ & 12 \\
MEMS + questionnaire & 55 & 44 & 25 & 16 & 13 \\
Blood sample + questionnaire & $\mathrm{x}$ & 41 & 26 & $\mathrm{x}$ & 12 \\
MEMS + blood sample + questionnaire & $\mathrm{x}$ & 39 & 24 & $\mathrm{x}$ & 11 \\
\hline
\end{tabular}

MEMS, medication event monitoring system; T0, baseline; T1, T2, T3 and T4 represent time-points 1, 2, 3 and 4 months

Table 2 Baseline characteristics

\begin{tabular}{lll}
\hline & $n^{\mathrm{a}}$ & $\%$ \\
\hline Age median (years) & 62 & 63.5 \\
$\quad$ Range & $46-80$ & \\
Male & 62 & 53.2 \\
Low education & 60 & 40.0 \\
Living alone & 62 & 14.5 \\
Paid work & 58 & 17.2 \\
Smoking & 62 & 19.4 \\
Co-morbidity & 61 & 65.6 \\
Co-medication & 62 & 82.3 \\
Number of drugs & 51 & \\
Mean \pm SD & $5.0 \pm 2.8$ & \\
Range & $1-13$ & \\
Initial erlotinib dose $150 \mathrm{mg}$ & 60.3 \\
Duration of use (days) & 62 & \\
Mean \pm SD & $58.3 \pm 39.4$ & \\
Range & $2-120^{\mathrm{b}}$ & \\
\hline
\end{tabular}

$S D$ standard deviation

${ }^{\text {a }}$ Number of patients with data available

${ }^{\mathrm{b}}$ Maximum observation period was 120 days

(53\%) before 2 months. Table 1 provides information on the number of patients for which data are available at specific time-points. The median duration of treatment of the 62 patients was 51.5 days, with a range from 2 days to the maximum of the observation period of 120 days. Baseline characteristics of the patients are shown in Table 2.

\section{Medication adherence}

Most patients (55/62, $89 \%)$ used MEMS during the observation period. Two patients refused to use MEMS, three patients used erlotinib $<7$ days and the MEMS data of another 2 patients were not evaluable due to technical problems. The mean PDC during the observation period was $96.8 \pm 4.0 \%$, with a range from 85 to $100 \%$ (Table 3 ). Over one-third of patients (19/55) covered $<95 \%$ of days. Thirty-four patients (62\%) had at least one day with multiple openings. The mean PDMO of these patients during the studied period was $5.6 \pm 4.8 \%$, with a range from 1 to $21 \%$. The mean adherence measured with MARS (scale 5-25) was $24.9 \pm 0.4$ after 1 month and remained above 24 on the other time-points. The MARS statements showed 3 patients $(5 \%)$ rarely forgetting to take their erlotinib, 1 patient $(2 \%)$ rarely adjusting the dose and 1 patient $(2 \%)$ temporarily stopping. 1 patient $(2 \%)$ reported to rarely use more than prescribed.

Quality of life and patients' beliefs and attitude

The mean score at baseline of the SF-12 physical component was $32.5 \pm 9.3$, and the SF-12 mental component was $47.7 \pm 8.2$. The BMQ subscales were $10.8 \pm 2.6$ (overuse), $10.3 \pm 2.3$ (harm), $19.1 \pm 3.2$ (necessity), $15.3 \pm 4.0$ (concerns) and $4.0 \pm 4.5$ (differential). The classification into 4 attitudinal groups based on their responses to the BMQ at baseline was: $40.0 \%$ accepting (high necessity, low concerns), $55.0 \%$ ambivalent (high necessity, high concerns), $3.3 \%$ indifferent (low necessity, low concerns) and $1.7 \%$ sceptical (low necessity, high concerns). The mean scores of Brief IPQ at baseline were $8.0 \pm 1.9$ (consequences), $8.5 \pm 2.5$ (time line), $4.0 \pm 2.8$ (personal control), $6.4 \pm 2.3$ (treatment control), $7.9 \pm 2.3$ (identity), $6.0 \pm 2.8$ (concern), $5.7 \pm 3.3$ (understanding) and $5.4 \pm 2.9$ (emotional response).

Symptoms

Patient-reported symptoms are listed in Table 4 . The most reported symptoms at baseline were fatigue $(89 \%)$, emotional symptoms (anger, fear, depression and/or mood swings) (74\%), dyspnoea (71\%) and cough (70\%). After 1 month of treatment, fatigue (91\%), rash (86\%), cough (77\%), anorexia (74\%), emotional symptoms (67\%), dyspnoea $(66 \%)$ and diarrhoea $(66 \%)$ were the symptoms most commonly reported. Fatigue was the symptom most commonly occurring at baseline (89\%) and during treatment $(91,83,88$ and $85 \%$ at, respectively, 1, 2, 3 and 4 months). Severe symptoms most commonly reported after 1 month of treatment were rash (39\%), fatigue (32\%), sleeping problems (29\%) and anorexia (21\%).

Table 5 shows the change in patient-reported symptoms over time for patients with at least 2 months of follow-up.

Patient-reported symptoms mentioned after 1 month ( $n=49)$ were compared with adverse events observed in the pivotal phase III BR.21 study (Shepherd et al. 2005) 
Table 3 Adherence to erlotinib as measured with MEMS

\begin{tabular}{|c|c|c|c|c|}
\hline & $n$ & Mean \pm SD & Median & Range \\
\hline Duration of use (days) & 55 & $60.2 \pm 38.8$ & 52.0 & $6.0-120.0$ \\
\hline PDC & 55 & $96.8 \pm 4.0$ & 98.0 & $85.0-100.0$ \\
\hline PDC (period 0-28 days) & 55 & $97.5 \pm 5.0$ & 100.0 & $71.4-100.0$ \\
\hline PDC (period 29-56 days) & 39 & $96.5 \pm 6.4$ & 100.0 & $71.4-100.0$ \\
\hline PDC (period 57-max 120 days) & 25 & $95.2 \pm 6.7$ & 100.0 & $75.0-100.0$ \\
\hline PDMO & 34 & $5.6 \pm 4.8$ & 4.1 & $1.0-21.2$ \\
\hline & \multicolumn{4}{|c|}{$\%$} \\
\hline $100 \%$ PDC & 55 & & \multicolumn{2}{|c|}{43.6} \\
\hline$\geq 95 \% \mathrm{PDC}$ & 55 & & \multicolumn{2}{|c|}{65.5} \\
\hline$\geq 90 \%$ PDC & 55 & & \multicolumn{2}{|c|}{92.7} \\
\hline
\end{tabular}

$P D C$ proportion of days covered, $P D M O$ proportion of days with multiple openings, $S D$ standard deviation, $M E M S$ medication event monitoring system

Table 4 Patient-reported symptoms

\begin{tabular}{|c|c|c|c|c|c|c|c|c|c|c|c|c|c|c|}
\hline \multirow[t]{3}{*}{$n$} & \multicolumn{5}{|c|}{$\%$ any } & \multicolumn{5}{|c|}{$\%$ severe $^{\mathrm{a}}$} & \multicolumn{4}{|c|}{$\%$ increase $^{\mathrm{b}}$} \\
\hline & $T 0$ & $T 1$ & $T 2$ & $T 3$ & $T 4$ & $T 0$ & $T 1$ & $T 2$ & $T 3$ & $T 4$ & $T 1$ & $T 2$ & $T 3$ & $T 4$ \\
\hline & 62 & 49 & 29 & 17 & 15 & 62 & 49 & 29 & 17 & 15 & 49 & 29 & 17 & 15 \\
\hline Fatigue & 88.5 & 90.9 & 82.6 & 88.2 & 84.6 & 26.2 & 31.8 & 17.4 & 17.6 & 23.1 & 21.7 & 52.2 & 58.8 & 53.8 \\
\hline Rash & 14.8 & 81.8 & 87.0 & 82.4 & 84.6 & 3.3 & 38.6 & 30.4 & 29.4 & 38.5 & 81.8 & 81.8 & 81.3 & 91.7 \\
\hline Anorexia & 54.8 & 70.5 & 60.9 & 52.9 & 61.5 & 8.1 & 20.5 & 21.7 & 23.5 & 15.4 & 39.1 & 39.1 & 35.3 & 23.1 \\
\hline Diarrhoea & 19.4 & 65.9 & 65.2 & 52.9 & 76.9 & 1.6 & 11.4 & 13.0 & 17.6 & 15.4 & 56.5 & 52.2 & 52.9 & 69.2 \\
\hline Ocular symptoms & 26.2 & 59.1 & 39.1 & 35.3 & 69.2 & 0 & 4.5 & 4.3 & 0 & 0 & 36.4 & 22.7 & 18.8 & 41.7 \\
\hline Nausea/vomiting & 23.0 & 51.2 & 30.4 & 23.5 & 23.1 & 6.6 & 14.6 & 4.3 & 5.9 & 0 & 33.3 & 28.6 & 12.5 & 8.3 \\
\hline Stomatitis & 3.3 & 22.0 & 14.3 & 29.4 & 38.5 & 0 & 7.3 & 4.8 & 5.9 & 7.7 & 16.7 & 11.1 & 31.3 & 41.7 \\
\hline Infection & 1.7 & 11.6 & 8.7 & 17.6 & 41.7 & 0 & 2.3 & 0 & 5.9 & 8.3 & 0.0 & 4.5 & 18.8 & 36.4 \\
\hline Cough & 70.0 & 76.7 & 77.3 & 64.7 & 53.8 & 5.0 & 9.3 & 9.1 & 0 & 23.1 & 20.0 & 35.0 & 12.5 & 33.3 \\
\hline Dyspnoea & 71.0 & 65.9 & 60.9 & 64.7 & 66.7 & 9.7 & 18.2 & 8.7 & 17.6 & 25.0 & 26.1 & 39.1 & 41.2 & 41.7 \\
\hline Sleep problems & 47.5 & 45.5 & 39.1 & 53.3 & 46.2 & 13.1 & 28.6 & 4.3 & 13.3 & 15.4 & 13.6 & 13.6 & 26.7 & 23.1 \\
\hline Emotional symptoms & 74.1 & 67.4 & 56.5 & 70.6 & 69.2 & 13.6 & 13.6 & 4.3 & 5.9 & 15.4 & 33.3 & 28.6 & 40.0 & 36.4 \\
\hline Stomach ache & 23.0 & 37.2 & 43.5 & 47.1 & 30.8 & 4.9 & 2.3 & 0 & 0 & 0 & 19.0 & 38.1 & 37.5 & 25.0 \\
\hline Headache & 31.3 & 20.5 & 21.7 & 11.8 & 30.8 & 3.3 & 0 & 0 & 0 & 0 & 4.5 & 9.1 & 6.3 & 16.7 \\
\hline Pain when breathing & 13.1 & 14.0 & 17.4 & 25.0 & 15.4 & 0 & 0 & 0 & 0 & 7.7 & 0.0 & 13.6 & 13.3 & 8.3 \\
\hline
\end{tabular}

Missing data excluded from frequency analyses

T0, at baseline; T1, at 1 month; T2, at 2 months; T3, at 3 months; T4, at 4 months

a $\%$ of patients with symptoms reported as 'a lot' or 'very much'

b $\%$ of patients with a (any grade) symptom score higher than the score at baseline

(Table 6). Though not significantly different from the toxicities reported in BR.21 $(p>0.05)$, the occurrence of most patient-reported symptoms (fatigue, rash, anorexia, diarrhoea, nausea/vomiting and stomatitis) was higher than the adverse events scored by clinicians in the BR.21 study. Ocular symptoms were reported more frequently by patients in the present study and infection less often as compared to BR.21 $(p<0.05)$.
Adherence and use in daily practice

Most patients (>70 \%) reported to use any reminder method to support the erlotinib intake. None of the patients reported the intake of grapefruit or grapefruit juice during treatment with erlotinib. No relationship was found between adherence (assessed with MEMS) and the use of a reminder method. After 1 month, $21 \%$ of patients did not 
Table 5 Longitudinal description of patient-reported symptoms
T0, at baseline; T1, at 1 month; $\mathrm{T} 2$, at 2 months

\begin{tabular}{|c|c|c|c|c|c|c|}
\hline \multirow[t]{2}{*}{$(n=29)$} & \multicolumn{2}{|l|}{$T 0$} & \multicolumn{2}{|l|}{$T 1$} & \multicolumn{2}{|l|}{$T 2$} \\
\hline & $\%$ any & $\%$ severe & $\%$ any & $\%$ severe & $\%$ any & $\%$ severe \\
\hline Fatigue & 82.6 & 25.0 & 87.0 & 20.7 & 82.6 & 17.4 \\
\hline Rash & 9.1 & 0 & 86.4 & 24.7 & 86.4 & 30.4 \\
\hline Anorexia & 56.5 & 3.4 & 73.9 & 13.8 & 60.9 & 21.7 \\
\hline Diarrhoea & 17.4 & 0 & 69.6 & 10.3 & 65.2 & 13.0 \\
\hline Ocular symptoms & 22.7 & 0 & 54.5 & 3.4 & 36.4 & 4.3 \\
\hline Nausea/vomiting & 19.0 & 7.1 & 38.1 & 10.7 & 28.6 & 4.3 \\
\hline Stomatitis & 0.0 & 0 & 16.7 & 3.7 & 11.1 & 4.8 \\
\hline Infection & 0.0 & 0 & 0.0 & 0 & 4.5 & 0 \\
\hline Cough & 70.0 & 7.4 & 75.0 & 7.1 & 75.0 & 9.1 \\
\hline Dyspnoea & 65.2 & 6.9 & 52.2 & 10.3 & 60.9 & 8.7 \\
\hline Sleep problems & 50.0 & 10.7 & 40.9 & 10.3 & 40.9 & 4.3 \\
\hline Emotional symptoms & 76.2 & 7.7 & 57.1 & 10.3 & 57.1 & 4.3 \\
\hline Stomach ache & 4.8 & 0 & 23.8 & 3.6 & 42.9 & 0 \\
\hline Headache & 31.8 & 0 & 22.7 & 3.4 & 18.2 & 0 \\
\hline Pain when breathing & 18.2 & 0 & 4.5 & 0 & 13.6 & 0 \\
\hline
\end{tabular}

Table 6 Patient-reported symptoms versus clinical trial adverse events**

\begin{tabular}{llllllc}
\hline$T 1$ & \multicolumn{2}{l}{ PRO } & & \multicolumn{2}{c}{ Clinical trial $^{\mathrm{a}}$} & $p$ value \\
\cline { 2 - 3 } & $n$ & $\%$ & & $n$ & $\%$ & \\
\hline Fatigue & 44 & 90.9 & & 485 & 79 & 0.075 \\
Rash & 44 & 81.8 & & 485 & 76 & 0.461 \\
Anorexia & 44 & 70.5 & & 485 & 69 & 0.057 \\
Diarrhoea & 44 & 65.9 & & 485 & 55 & 0.205 \\
Ocular symptoms & 44 & 59.1 & & 485 & 28 & $<0.001^{*}$ \\
Nausea/vomiting & 41 & 51.2 & & 485 & 40 & 0.186 \\
Stomatitis & 41 & 22.0 & & 485 & 19 & 0.679 \\
Infection & 43 & 11.6 & & 485 & 34 & $<0.001^{*}$ \\
\hline
\end{tabular}

PRO patient-reported outcomes

* Significant; T1, at 1 month; ** symptoms scored by patients in this study and adverse events scored by clinicians in the BR.21 trial (CTCAE vs. 2) independent of severity

${ }^{\text {a }}$ BR.21 trial (Shepherd et al. 2005)

always correctly take erlotinib without food. Tables 7 and 8 show the risk factors of not always taking erlotinib under fasting conditions. Significant relationships with incorrect intake were: older age (OR 1.10, $95 \%$ CI 1.00-1.21), MARS < 25 (OR 4.83, $95 \%$ CI 1.06-21.99), oculair symptoms (OR 3.13, $95 \%$ CI 1.11-8.82) and stomatitis (OR $6.59,95 \%$ CI 1.77-24.60).

\section{AUC}

The mean $\operatorname{AUC}_{\mathrm{ss}}(\mu \mathrm{g} * \mathrm{~h} / \mathrm{mL})$ of erlotinib at 1,2 and 4 months of treatment was $37.8 \pm 15.7(n=42)$,
Table 7 Relations with incorrect intake of erlotinib under fasting conditions $^{\mathrm{a}}$

\begin{tabular}{llll}
\hline$N=41$ & OR & $95 \%$ CI & $p$ value \\
\hline Male & 1.20 & $0.30-4.80$ & 0.797 \\
Age & 1.10 & $1.00-1.21$ & $0.041^{*}$ \\
Low education & 3.00 & $0.69-13.12$ & 0.144 \\
Living alone & 0.50 & $0.05-4.83$ & 0.549 \\
No paid work & 2.86 & $0.31-26.74$ & 0.356 \\
No smoking & 1.54 & $0.15-15.49$ & 0.715 \\
No Co-morbidity & 2.80 & $0.68-11.59$ & 0.155 \\
Number of co-medication & 0.96 & $0.75-1.22$ & 0.717 \\
\hline
\end{tabular}

Missing data excluded from analyses

$O R$ odds ratio, $C I$ confidence interval

* Significant

a Analyses of baseline characteristics using logistic regression

$36.8 \pm 15.8(n=28)$ and $40.5 \pm 20.4(n=13)$, respectively. The relationship between the AUC and patientreported symptoms at 1 month is presented in Table 9 . The mean AUC of erlotinib was significantly higher in patients who reported rash (any severity) $(p<0.05)$. The comparison of the AUC of erlotinib in patients reporting symptoms at the levels 'not at all' or 'a little bit' (no and mild) with the AUC in those reporting symptoms at the levels 'rather', 'a lot', or 'very much' (moderate and severe) at 1 month was only significantly different for anorexia. Patients reporting moderate or severe anorexia had a significantly higher AUC than patients reporting no or mild anorexia $(44.8 \pm 4.7$ vs. $33.5 \pm 2.7 \mu \mathrm{g} * \mathrm{~h} / \mathrm{mL}$, $p<0.05)$. A substantial number of patients $(39 \%)$ used 
Table 8 Relations with incorrect intake of erlotinib under fasting conditions $^{\mathrm{a}}$

\begin{tabular}{|c|c|c|c|}
\hline$N=40$ & OR & $95 \% \mathrm{CI}$ & $p$ value \\
\hline \multicolumn{4}{|l|}{ SF-12 } \\
\hline Physical component & 1.00 & $0.99-1.01$ & 0.959 \\
\hline Mental component & 1.02 & $1.00-1.04$ & 0.079 \\
\hline \multicolumn{4}{|l|}{ BMQ } \\
\hline General overuse & 0.97 & $0.92-1.02$ & 0.279 \\
\hline General harm & 0.97 & $0.92-1.03$ & 0.306 \\
\hline Specific necessity & 1.01 & $0.97-1.04$ & 0.774 \\
\hline Specific concerns & 0.99 & $0.97-1.02$ & 0.593 \\
\hline Necessity-concerns differential & 1.00 & $0.99-1.02$ & 0.564 \\
\hline \multicolumn{4}{|l|}{ Brief IPQ } \\
\hline Consequences & 1.01 & $0.97-1.04$ & 0.691 \\
\hline Time line & 1.01 & $0.96-1.07$ & 0.588 \\
\hline Personal control & 0.97 & $0.94-1.00$ & 0.085 \\
\hline Treatment control & 1.03 & $0.96-1.11$ & 0.374 \\
\hline Identity & 1.02 & $0.97-1.06$ & 0.417 \\
\hline Concern & 0.97 & $0.94-1.01$ & 0.124 \\
\hline Understanding & 0.98 & $0.95-1.02$ & 0.313 \\
\hline Emotional response & 0.99 & $0.96-1.02$ & 0.449 \\
\hline MARS $<25$ & 4.83 & $1.06-21.99$ & $0.042 *$ \\
\hline No reminder method & 2.79 & $0.52-14.82$ & 0.229 \\
\hline \multicolumn{4}{|c|}{ Patient-reported symptom (any severity) } \\
\hline Rash & 2.52 & $0.44-14.21$ & 0.295 \\
\hline Anorexia & 0.36 & $0.11-1.20$ & 0.097 \\
\hline Diarrhoea & 8.16 & $0.43-154.09$ & 0.161 \\
\hline Ocular symptoms & 3.13 & $1.11-8.82$ & $0.031^{*}$ \\
\hline Nausea/vomiting & 0.62 & $0.13-3.02$ & 0.554 \\
\hline Stomatitis & 6.59 & $1.77-24.60$ & $0.005 *$ \\
\hline Infection & 1.18 & $0.12-12.02$ & 0.891 \\
\hline Cough & 0.32 & $0.08-1.25$ & 0.102 \\
\hline Dyspnoea & 5.69 & $0.83-38.87$ & 0.076 \\
\hline Sleep problems & 0.59 & $0.15-2.32$ & 0.454 \\
\hline Stomach ache & 1.69 & $0.44-6.50$ & 0.445 \\
\hline Headache & 0.95 & $0.18-4.99$ & 0.956 \\
\hline Pain when breathing & 0.49 & $0.08-3.04$ & 0.443 \\
\hline
\end{tabular}

No OR could be estimated for fatigue and emotional symptoms. Missing data excluded from analyses

$O R$ odds ratio, $C I$ confidence interval, $S F-12$ short form-12 health survey, $B M Q$ beliefs about medicines questionnaire, Brief IPQ illness perception questionnaire, MARS medication adherence report scale

* Significant

a Analyses using generalized estimated equations (GEE)

an acid-inhibiting drug (a proton-pump inhibitor or a histamine H2-receptor antagonist). The AUC of erlotinib of this patient group did not differ between those who did use and those who did not use acid-inhibiting medication (AUC, respectively, $34.5 \pm 13.4$ vs. $41.4 \pm 19.1 \mu \mathrm{g} * \mathrm{~h} /$ $\mathrm{mL}, p=0.283)$.
Discontinuation

Twenty-six patients filled out the questions on reasons for discontinuation. Thirty-one per cent of them reported side effects as a reason to stop erlotinib treatment, whereas $69 \%$ stopped treatment because of lack of clinical efficacy. Most patients ( $88 \%$ ) discontinued on the initiative of their physician.

\section{Discussion}

NSCLC patients prescribed erlotinib were highly compliant. The mean adherence was $96.8 \% \pm 4.0$.

The high adherence rate might be explained by the lifethreatening nature of the disease and the short treatment period. Sub-optimal adherence to oral anticancer medication is more often an issue in long-term treatments, such as adjuvant endocrine treatment prescribed after primary breast cancer or TKI treatment of chronic myeloid leukaemia (Ruddy et al. 2009; Marin et al. 2010; Partridge et al. 2010). The median duration of treatment with erlotinib in the present study was 52 days, mainly driven by lack of clinical efficacy. Treatment duration was grossly comparable with that in unselected patients on erlotinib in the BR.21 trial in whom a progression-free survival was measured of 2.2 months (Shepherd et al. 2005). In our study, erlotinib patients were included without knowledge of the EGFR mutation status in tumour tissue. As erlotinib is now increasingly used in pre-selected patients, the duration of use may increase. This might negatively influence adherence.

In the present study, $93 \%$ of the patients had a PDC of at least $90 \%$. However, over one-third of all patients used erlotinib in $<95 \%$ of the prescribed days. Adherence rates of $80-95 \%$ are generally considered as a minimum to obtain an optimal medication efficacy (Osterberg and Blaschke 2005; Ruddy et al. 2009). Adherence $<95 \%$, measured with the self-report Basel Assessment of Adherence Scale (BAAS), has previously been shown related to poorer rates of response to erlotinib (Gebbia et al. 2013). The considerable number of patients $(34.5 \%)$ who had a PDC below $95 \%$ confirms that medication adherence might be a relevant issue for this drug.

A minority of patients $(21 \%)$ reported occasionally not to follow the recommendations regarding the intake of erlotinib under fasting conditions. Erlotinib should be swallowed at least $1 \mathrm{~h}$ before or $2 \mathrm{~h}$ after intake of a meal (EMA 2014). Intake under fasting conditions is necessary because food can substantially increase erlotinib plasma levels (Ling et al. 2008), which may cause undesirable adverse events. The presence of stomatitis was significantly related with sub-optimal intake relative to time-points of a 
Table 9 Relationship between $\mathrm{AUC}_{\mathrm{ss}}$ and patient-reported symptoms (T1)

\begin{tabular}{|c|c|c|c|c|c|}
\hline \multirow{2}{*}{$\begin{array}{l}(n=41) \\
\text { Symptom }\end{array}$} & \multicolumn{2}{|c|}{$\begin{array}{l}\text { No symptom AUC } \\
(\mu \mathrm{g} * \mathrm{~h} / \mathrm{mL})\end{array}$} & \multicolumn{2}{|c|}{$\begin{array}{l}\text { Symptom AUC } \\
(\mu \mathrm{g} * \mathrm{~h} / \mathrm{mL})\end{array}$} & \multirow[t]{2}{*}{$p$ value } \\
\hline & $n$ & Mean \pm SD & $n$ & Mean \pm SD & \\
\hline Fatigue & 4 & $26.2 \pm 3.0$ & 34 & $39.3 \pm 2.8$ & 0.074 \\
\hline Rash & 7 & $27.8 \pm 4.7$ & 31 & $40.2 \pm 2.8$ & $0.030 *$ \\
\hline Anorexia & 11 & $32.4 \pm 4.8$ & 27 & $40.2 \pm 3.0$ & 0.082 \\
\hline Diarrhoea & 14 & $35.5 \pm 4.4$ & 24 & $39.4 \pm 3.2$ & 0.520 \\
\hline $\begin{array}{l}\text { Ocular symp- } \\
\text { toms }\end{array}$ & 18 & $39.6 \pm 4.6$ & 20 & $36.4 \pm 2.6$ & 0.919 \\
\hline \multicolumn{2}{|c|}{ Nausea/vomiting 16} & $33.6 \pm 2.7$ & 19 & $42.3 \pm 4.4$ & 0.286 \\
\hline Stomatitis & 28 & $36.8 \pm 2.6$ & 8 & $43.3 \pm 8.4$ & 0.614 \\
\hline Infection & 33 & $38.3 \pm 2.9$ & 4 & $34.8 \pm 6.0$ & 0.944 \\
\hline Cough & 7 & $35.2 \pm 3.6$ & 30 & $39.3 \pm 3.1$ & 0.747 \\
\hline Dyspnoea & 13 & $32.7 \pm 3.4$ & 25 & $40.7 \pm 3.4$ & 0.188 \\
\hline Sleep problems & 20 & $35.6 \pm 2.9$ & 18 & $40.6 \pm 4.4$ & 0.534 \\
\hline $\begin{array}{l}\text { Emotional symp- } \\
\text { toms }\end{array}$ & -11 & $34.3 \pm 4.6$ & 26 & $39.7 \pm 3.2$ & 0.256 \\
\hline Stomach ache & 23 & $38.6 \pm 3.9$ & 15 & $36.9 \pm 2.9$ & 0.768 \\
\hline Headache & 31 & $37.4 \pm 3.0$ & 7 & $40.3 \pm 5.0$ & 0.354 \\
\hline $\begin{array}{l}\text { Pain when } \\
\text { breathing }\end{array}$ & 31 & $38.8 \pm 3.1$ & 6 & $36.9 \pm 2.5$ & 0.888 \\
\hline
\end{tabular}

Missing data excluded from analyses

$\mathrm{AUC}_{\mathrm{ss}}$, area under the curve at steady state; T1, at 1 month; SD, standard deviation

* Significant

meal (OR 6.59, $p=0.005$ ). Stomatitis may influence the eating habits and result in an irregular or complex schedule of separation of medication from food. Sub-optimal adherence (MARS < 25) was also significantly related with suboptimal intake relative to time-points of a meal (OR 4.83, $p=0.042)$. This can be expected, since incorrect intake relative to time-points of a meal, is an aspect of sub-optimal adherence. Older age (OR 1.10, $p=0.041)$ and ocular symptoms (OR 3.13, $p=0.031$ ) might also have contributed to non-adherence. Particularly in case of stomatitis, food intake during the use of erlotinib should be carefully addressed by healthcare professionals, on the one hand, to support patients in correctly taking erlotinib in the absence of food and, on the other hand, to avoid anorexia.

As expected, NSCLC patients experienced a variety of symptoms. At baseline, their physical quality of life score was considerably lower $(32.5 \pm 9.3)$ than reported for the general population in the Netherlands $(47.9 \pm 0.6$ for 45- to 64-year-olds; $45.2 \pm 10.5$ for 65 - to 74-year-olds). This also holds for the mean mental score $(47.7 \pm 8.2 \mathrm{vs}$. $51.4 \pm 9.6$ for 45 - to 64-year-olds and $52.9 \pm 8.6$ for 65 to 74-year-olds (Gandek et al. 1998). The distribution of patients across the four BMQ-belief groups in our population shows the majority of patients being ambivalent (high necessity, high concerns). This is different from patients with the diseases asthma, cardiac disease, depression or diabetes, where most patients had an accepting (high necessity, low concerns) attitude towards medication (Tibaldi et al. 2009). The severity of the disease and expected symptoms experienced during treatment might play an important role in the high concerns about the medication.

An important issue to address is the role of patients in the assessment of health problems and symptoms to obtain insight into side effects they experience from drug medication (Basch 2010). Advanced NSCLC patients using erlotinib report many health problems, which may not only be caused by their medication but also result from their disease and its progress. In oncology, the collection of data on side effects is clinician based and highly regulated by the CTCAE system (Trotti et al. 2007). A comparison of patient-reported symptoms which occurred in the present real-world study with adverse event data from the clinical trial on erlotinib in NSCLC patients confirms the usefulness of patient-reported outcomes (Basch et al. 2009, 2012; Basch 2010). Although most symptoms did not significantly differ from those scored by clinicians, especially symptoms in the less specific domain were reported more often by patients. Patients' experiences should always be taken into account, since one-third of the patients reported symptoms as one of the reasons to discontinue treatment. This finding is in line with the results of a previous study in patients using oral anticancer agents (Timmers et al. 2014). Since $88 \%$ of patients discontinued on the initiative of their physician, symptoms reported by the patient may very well have coincided with lack of benefit from erlotinib.

The mean AUC of erlotinib was higher in patients who reported rash (any severity), $p<0.05$. The relationship between erlotinib exposure and skin rash has been demonstrated previously (Lu et al. 2006; Rudin et al. 2008; Thomas et al. 2009), though the absence of a link between exposure and rash was found as well (Mita et al. 2011). Skin rash is a sign used in clinical practice as indicative for clinical benefit since patients with a high grade of skin rash may experience a longer progression-free and overall survival (Krawczyk et al. 2013; Perez-Soler et al. 2004; Petrelli et al. 2012b; Wacker et al. 2007), though dosing till rash to optimize efficacy is controversial (Mita et al. 2011; Brahmer et al. 2014).

Nowadays, erlotinib is prescribed preferentially for treatment of selected NSCLC patients. The presence of activating EGFR gene mutations and high EGFR gene copy number are predictors of an improved clinical outcome, while the role of KRAS mutations still needs to be elucidated (Zhu et al. 2008; Cadranel et al. 2012). Currently, it is advised to assess the EGFR status before starting firstline treatment with erlotinib (Brugger et al. 2011; Califano et al. 2012). The use of erlotinib in second-line treatment 
of EGFR wild-type NSCLC patients is an ongoing debate as erlotinib seems less effective than docetaxel (Garassino et al. 2013). With a better understanding of the presence of genetic mutations as a prerequisite for response, the need to use skin rash as a predictor for clinical outcome has become of less importance.

Apart from rash, the mean AUC of erlotinib was also higher in patients reporting moderate or severe anorexia. For other symptoms, such as mucositis, diarrhoea, ocular symptoms and fatigue, frequently reported with the use of erlotinib (Table 4), there was no apparent relationship with the AUC. The use of acid-inhibiting co-medication (i.e. proton-pump inhibitors and/or histamine H2-receptor antagonists) resulted in a lower mean AUC in the present study, though this effect was not significant. It is recommended not to combine erlotinib with gastric acid-suppressive medication because it can reduce bioavailability (EMA 2014). However, a recently performed retrospective analysis of the BR.21 trial database to evaluate the clinical impact of this interaction showed that acid-inhibiting comedication had no significant impact on plasma levels or outcome (Hilton et al. 2013).

The present study has some strengths and limitations. It provides a unique and complete survey of the use of erlotinib from the patients' perspective. To our knowledge, adherence to erlotinib neither has been studied previously, nor have real-life data, erlotinib blood samples, patients' experiences, data retrieved from the patient's medical file and pharmacies, and adherence assessed with MEMS has been combined in a single study. Unfortunately, the number of included patients is limited. The study was performed in an unselected NSCLC patient population, resulting in a relatively short observation period.

\section{Conclusion}

Medication adherence to erlotinib is an issue in a considerable number of patients with advanced NSCLC. Patients report to have many health problems at baseline and, as to be expected, new symptoms appear during erlotinib treatment. To support patients' optimal erlotinib intake, clinicians need to take adequate measures to ameliorate symptoms and to address medication adherence and correct intake without food. Especially older patients and those who experience stomatitis may need extra attention to support a correct erlotinib use in daily practice.

Acknowledgments The authors thank the participating centres in the Netherlands: Amphia ziekenhuis, Breda; Kennemer Gasthuis, Haarlem; Sint Franciscus Gasthuis, Rotterdam; Medisch Centrum Alkmaar, Alkmaar; Rode Kruis Ziekenhuis, Beverwijk; Jeroen Bosch Ziekenhuis, 's-Hertogenbosch; Westfries Gasthuis, Hoorn; Spaarne Ziekenhuis, Hoofddorp; Meander Medisch Centrum, Amersfoort; Sint
Lucas Andreas Ziekenhuis, Amsterdam; Leids Universitair Medisch Centrum, Leiden. Furthermore, we thank the patients who participated in this study.

Conflict of interest Roche, The Netherlands, provided an unrestricted grant. LT received an unrestricted grant from Stichting PRISMA Albert Bakker Fonds. The authors declare that they have no conflicts of interest.

Open Access This article is distributed under the terms of the Creative Commons Attribution License which permits any use, distribution, and reproduction in any medium, provided the original author(s) and the source are credited.

\section{References}

Aaronson NK, Muller M, Essink-Bot ML, Fekkes M, Sanderman R, te Velde A, Verrips E (1998) Translation, validation, and norming of the Dutch Language Version of the SF-36 Health Survey in Community and Chronic Disease Populations. J Clin Epidemiol 51:1055-1068

Basch E (2010) The missing voice of patients in drug-safety reporting. N Engl J Med 362:865-869

Basch E, Jia X, Heller G, Barz A, Sit L, Fruscione M, Appawu M, Iasonos A, Atkinson T, Goldfarb S, Culkin A, Kris MG, Schrag D (2009) Adverse symptom event reporting by patients vs clinicians: relationships with clinical outcomes. J Natl Cancer Inst 101:1624-1632

Basch E, Abernethy AP, Mullins CD, Reeve BB, Smith ML, Coons SJ, Sloan J, Wenzel K, Chauhan C, Eppard W, Frank ES, Lipscomb J, Raymond SA, Spencer M, Tunis S (2012) Recommendations for incorporating patient-reported outcomes into clinical comparative effectiveness research in adult oncology. J Clin Oncol 30:4249-4255

Bezjak A, Tu D, Seymour L, Clark G, Trajkovic A, Zukin M, Ayoub J, Lago S, de Albuquerque Ribeiro R, Gerogianni A, Cyjon A, Noble J, Laberge F, Chan RT, Fenton D, von Pawel J, Reck M, Shepherd FA (2006) Symptom improvement in lung cancer patients treated with erlotinib: quality of life analysis of the National Cancer Institute of Canada Clinical Trials Group Study BR.21. J Clin Oncol 24:3831-3837

Brahmer JR, Lee JW, Traynor AM, Hidalgo MM, Kolesar JM, Siegfried JM, Guaglianone PP, Patel JD, Keppen MD, Schiller JH (2014) Dosing to rash: a phase II trial of the first-line erlotinib for patients with advanced non-small-cell lung cancer an Eastern Cooperative Oncology Group Study (E3503). Eur J Cancer 50:302-308

Broadbent E, Petrie KJ, Main J, Weinman J (2006) The brief illness perception questionnaire. J Psychosom Res 60:631-637

Brugger W, Triller N, Blasinska-Morawiec M, Curescu S, Sakalauskas R, Manikhas GM, Mazieres J, Whittom R, Ward C, Mayne K, Trunzer K, Cappuzzo F (2011) Prospective molecular marker analyses of EGFR and KRAS from a randomized, placebo-controlled study of erlotinib maintenance therapy in advanced nonsmall-cell lung cancer. J Clin Oncol 29:4113-4120

Butler JA, Peveler RC, Roderick P, Horne R, Mason JC (2004) Measuring compliance with drug regimens after renal transplantation: comparison of self-report and clinician rating with electronic monitoring. Transplantation 77:786-789

Cadranel J, Mauguen A, Faller M, Zalcman G, Buisine MP, Westeel V, Longchampt E, Wislez M, Coudert B, Daniel C, Chetaille B, Michiels S, Blons H, Solassol J, De Fraipont F, Foucher P, Urban T, Lacroix L, Poulot V, Quoix E, Antoine M, Danton G, Morin 
F, Chouaid C, Pignon JP (2012) Impact of systematic EGFR and KRAS mutation evaluation on progression-free survival and overall survival in patients with advanced non-small-cell lung cancer treated by erlotinib in a French prospective cohort (ERMETIC project-part 2). J Thorac Oncol 7:1490-1502

Califano R, Landi L, Cappuzzo F (2012) Prognostic and predictive value of K-RAS mutations in non-small cell lung cancer. Drugs 72(Suppl 1):28-36

EMA (2014) European Public Assessment Report Tarceva Product Information. European Medicines Agency

Gandek B, Ware JE, Aaronson NK, Apolone G, Bjorner JB, Brazier JE, Bullinger M, Kaasa S, Leplege A, Prieto L, Sullivan M (1998) Cross-validation of item selection and scoring for the SF-12 Health Survey in nine countries: results from the IQOLA Project. International Quality of Life Assessment. J Clin Epidemiol 51:1171-1178

Garassino MC, Martelli O, Broggini M, Farina G, Veronese S, Rulli E, Bianchi F, Bettini A, Longo F, Moscetti L, Tomirotti M, Marabese M, Ganzinelli M, Lauricella C, Labianca R, Floriani I, Giaccone G, Torri V, Scanni A, Marsoni S (2013) Erlotinib versus docetaxel as second-line treatment of patients with advanced non-small-cell lung cancer and wild-type EGFR tumours (TAILOR): a randomised controlled trial. Lancet Oncol 14:981-988

Gebbia V, Bellavia M, Banna GL, Russo P, Ferrau F, Tralongo P, Borsellino N (2013) Treatment monitoring program for implementation of adherence to second-line erlotinib for advanced nonsmall-cell lung cancer. Clin Lung Cancer 14:390-398

Hilton JF, Tu D, Seymour L, Shepherd FA, Bradbury PA (2013) An evaluation of the possible interaction of gastric acid suppressing medication and the EGFR tyrosine kinase inhibitor erlotinib. Lung Cancer 82:136-142

Horne R, Weinman J, Hankins M (1999) The beliefs about medicines questionnaire: the development and evaluation of a new method for assessing the cognitive representation of medication. Psychol Health 14:1-24

Horne R, Hankins M, Jenkins R (2001) The satisfaction with information about medicines scale (SIMS): a new measurement tool for audit and research. Q Health Care 10:135-140

Krawczyk P, Kowalski DM, Wojas Krawczyk K, Szczyrek M, Mlak R, Rolski A, Szudy A, Kieszko R, Winiarczyk K, Milanowski J, Krzakowski M (2013) Predictive and prognostic factors in second- and third-line erlotinib treatment in NSCLC patients with known status of the EGFR gene. Oncol Rep 30:1463-1472

Ling J, Fettner S, Lum BL, Riek M, Rakhit A (2008) Effect of food on the pharmacokinetics of erlotinib, an orally active epidermal growth factor receptor tyrosine-kinase inhibitor, in healthy individuals. Anticancer Drugs 19:209-216

Lu JF, Eppler SM, Wolf J, Hamilton M, Rakhit A, Bruno R, Lum BL (2006) Clinical pharmacokinetics of erlotinib in patients with solid tumors and exposure-safety relationship in patients with non-small cell lung cancer. Clin Pharmacol Ther 80:136-145

Marin D, Bazeos A, Mahon FX, Eliasson L, Milojkovic D, Bua M, Apperley JF, Szydlo R, Desai R, Kozlowski K, Paliompeis C, Latham V, Foroni L, Molimard M, Reid A, Rezvani K, de Lavallade H, Guallar C, Goldman J, Khorashad JS (2010) Adherence is the critical factor for achieving molecular responses in patients with chronic myeloid leukemia who achieve complete cytogenetic responses on imatinib. J Clin Oncol 28:2381-2388

Mita AC, Papadopoulos K, de Jonge MJ, Schwartz G, Verweij J, Mita MM, Ricart A, Chu QS, Tolcher AW, Wood L, McCarthy S, Hamilton M, Iwata K, Wacker B, Witt K, Rowinsky EK (2011) Erlotinib 'dosing-to-rash': a phase II intrapatient dose escalation and pharmacologic study of erlotinib in previously treated advanced non-small cell lung cancer. Br J Cancer 105:938-944
Osterberg L, Blaschke T (2005) Adherence to medication. N.Engl. J Med 353:487-497

Partridge AH, Avorn J, Wang PS, Winer EP (2002) Adherence to therapy with oral antineoplastic agents. J Natl Cancer Inst 94:652-661

Partridge AH, Archer L, Kornblith AB, Gralow J, Grenier D, Perez E, Wolff AC, Wang X, Kastrissios H, Berry D, Hudis C, Winer E, Muss H (2010) Adherence and persistence with oral adjuvant chemotherapy in older women with early-stage breast cancer in CALGB 49907: adherence companion study 60104. J Clin Oncol 28:2418-2422

Perez-Soler R, Chachoua A, Hammond LA, Rowinsky EK, Huberman M, Karp D, Rigas J, Clark GM, Santabarbara P, Bonomi P (2004) Determinants of tumor response and survival with erlotinib in patients with non-small-cell lung cancer. J Clin Oncol 22:3238-3247

Petrelli F, Borgonovo K, Cabiddu M, Barni S (2012a) Efficacy of EGFR tyrosine kinase inhibitors in patients with EGFR-mutated non-small-cell lung cancer: a meta-analysis of 13 randomized trials. Clin Lung Cancer 13:107-114

Petrelli F, Borgonovo K, Cabiddu M, Lonati V, Barni S (2012b) Relationship between skin rash and outcome in non-small-cell lung cancer patients treated with anti-EGFR tyrosine kinase inhibitors: a literature-based meta-analysis of 24 trials. Lung Cancer 78:8-15

Ruddy K, Mayer E, Partridge A (2009) Patient adherence and persistence with oral anticancer treatment. CA Cancer J Clin 59:56-66

Rudin CM, Liu W, Desai A, Karrison T, Jiang X, Janisch L, Das S, Ramirez J, Poonkuzhali B, Schuetz E, Fackenthal DL, Chen P, Armstrong DK, Brahmer JR, Fleming GF, Vokes EE, Carducci MA, Ratain MJ (2008) Pharmacogenomic and pharmacokinetic determinants of erlotinib toxicity. J Clin Oncol 26:1119-1127

Sabaté E (2003) Adherence to long-term therapies. Evidence for action. World Health Organisation, Geneva

Shepherd FA, Rodrigues PJ, Ciuleanu T, Tan EH, Hirsh V, Thongprasert S, Campos D, Maoleekoonpiroj S, Smylie M, Martins R, van Kooten M, Dediu M, Findlay B, Tu D, Johnston D, Bezjak A, Clark G, Santabarbara P, Seymour L (2005) Erlotinib in previously treated non-small-cell lung cancer. N Engl J Med 353:123-132

Thomas F, Rochaix P, White-Koning M, Hennebelle I, Sarini J, Benlyazid A, Malard L, Lefebvre JL, Chatelut E, Delord JP (2009) Population pharmacokinetics of erlotinib and its pharmacokinetic/pharmacodynamic relationships in head and neck squamous cell carcinoma. Eur J Cancer 45:2316-2323

Tibaldi G, Clatworthy J, Torchio E, Argentero P, Munizza C, Horne R (2009) The utility of the necessity-concerns framework in explaining treatment non-adherence in four chronic illness groups in Italy. Chronic Illn 5:129-133

Timmers L, Boons CCLM, Mangnus D, Moes JE, Swart EL, Boven E, Smit EF, Hugtenburg JG (2011) The use of erlotinib in daily practice: a study on adherence and patients' experiences. BMC Cancer 11:284

Timmers L, Boons CCLM, Kropff F, van de Ven PM, Swart EL, Smit EF, Zweegman S, Kroep JR, Timmer-Bonte JN, Boven E, Hugtenburg JG (2014) Adherence and patients' experiences with the use of oral anticancer agents. Acta Oncol 53:259-267

Trotti A, Colevas AD, Setser A, Basch E (2007) Patient-reported outcomes and the evolution of adverse event reporting in oncology. $\mathrm{J}$ Clin Oncol 25:5121-5127

Verbrugghe M, Verhaeghe S, Lauwaert K, Beeckman D, Van Hecke A (2013) Determinants and associated factors influencing medication adherence and persistence to oral anticancer drugs: a systematic review. Cancer Treat Rev 39:610-621

Wacker B, Nagrani T, Weinberg J, Witt K, Clark G, Cagnoni PJ (2007) Correlation between development of rash and efficacy in 
patients treated with the epidermal growth factor receptor tyrosine kinase inhibitor erlotinib in two large phase III studies. Clin Cancer Res 13:3913-3921

Zhu CQ, da Cunha Santos G, Ding K, Sakurada A, Cutz JC, Liu N, Zhang T, Marrano P, Whitehead M, Squire JA, Kamel-Reid S,
Seymour L, Shepherd FA, Tsao MS (2008) Role of KRAS and EGFR as biomarkers of response to erlotinib in National Cancer Institute of Canada Clinical Trials Group Study BR.21. J Clin Oncol 26:4268-4275 